\title{
DEVELOPMENT OF AN INSTRUMENT TO MEASURE FRACTION DIVISION OPERATION SENSE
}

\author{
Ali Alenazi \\ PhD., Department of Curriculum and Instruction, College of Education, Jazan University, \\ Saudi Arabia, alenazi@jazanu.edu.sa
}

\begin{abstract}
This study reports on the development of an instrument to measure fraction division operation sense. Internal content validity of the instrument was established following an extensive item creation and pilot testing. The instrument thereafter was administered to 113 pre-service teachers with an aim to evaluate its internal consistency reliability. Cronbach's alpha for the total score of instrument was .888 . To evaluate testretest reliability, 59 out of the 113 pre-service teachers used the instrument twice, 14 days apart. Pearson's correlation for the total score of instrument was .929. These results provide favorable evidence for the reliability of the instrument.
\end{abstract}

Keywords: Fraction, division, pre-service teachers, internal consistency, test-retest.

\section{INTRODUCTION}

Fraction concepts are connected to most topics in mathematics school learning. In fact, they are an essential part of the foundation that underlies complex mathematical topics. Petit, Laird, and Marsden (2010) stated that, "problems with learning fractions interfere with learning other mathematics topics and continue to pledge adults in daily tasks" (p.1).

To teach fractions for understanding, Huinker (2002) suggested the need to shift the goal of fraction instruction from learning computational rules to developing fraction operation sense. Operation sense is typically developed over time through understanding operations, properties of operations, and relations among them. Huinker suggested seven dimensions of operation sense that need to be mastered in order to learn fractions as well as whole numbers for understanding. These dimensions are: understanding the meanings and models of operations, understanding the effects of a operation on a pair of numbers, realworld applications, understanding the meaning and mathematical language associated with operations symbols language, ability to translate easily across the basic presentations of operations (i.e., real-world situations, oral language, and concrete, pictorial, and symbolic interpretations), understanding relationships between operations, and ability to compose and decompose numbers and use properties of operations to solve mathematical problems.

Although there have been numerous studies conducted on fraction operations in the past two decades, limited instruments for assessing fraction operation sense have been developed, especially fraction division 
operation sense. Faction division is considered one of the least understood fraction operations not only by children but also by pre-service teachers (Tirosh, 2000; Li \& Smith 2007). Pre-service teachers are often able to solve fraction division problems by applying algorithms, although they struggle to justify why these algorithms work. In light of this fact, there is a need for an instrument that would measure and monitor perservice teachers' development of fraction division operation sense. Since no such instrument could be found, it became necessary to develop one. This paper reports on the development of a fraction division operation sense instrument that could be used by educators to enhance pre-service teachers' knowledge of fraction division.

\section{INSTRUMENT}

\subsection{Fraction Division Operation Sense Framework}

Building on Huinker's work (2002), I reviewed the literature on students, teachers, and pre-service teachers' fraction division knowledge (e.g., Ball, 1990; Simon, 1993; Lubinski, Fox, \& Thomason, 1998; Ma, 1999; Tirosh, 2000; Nillas, 2003; Li \& Smith, 2007; Orrill, Araujo \& Jacobson, 2010) and accordingly formed a framework underlying specific dimensions and sub-dimensions of fraction division operation sense as follows:

1. Understanding the meaning and models of fraction division, including the following:

A. Measurement interpretation (how many times a quantity can be contained in another quantity).

B. Sharing interpretation (how much each group receives when the total quantity and number of groups are known).

C. Unit rate interpretation (determining the size of one group).

D. Division as the inverse of multiplication interpretation.

E. Division as the inverse of a Cartesian product interpretation (determining one dimension of a rectangular region where the area and the other dimension of the rectangular are know)

2. Understanding the effects of fraction division on a pair of numbers where fractions are involved:

A. Understanding that the answer does not always become smaller when dividing.

B. Understanding that the answer does not always become larger when multiplying.

3. Ability to perform real-world applications:

A. Recognizing real-world situations for fraction division operations.

B. Posing (designing) real-world situations for fraction division operations.

4. Understanding meanings and mathematical language associated with fraction division symbols:

A. Understanding that a number of different meanings can be derived from the same fraction division symbols.

B. Describing the different meanings attached to fraction division symbols by using the language of mathematics.

5. Ability to translate across various modes of interpretation (i.e., real-world situations, oral language, and concrete, pictorial, and symbolic interpretations):

A. Solving fraction division problems involving real-world contexts.

B. Fluently discussing fraction division problems and their solutions by using oral language and concrete, pictorial, and symbolic representations.

6. Understanding the relationships between fraction division and other operations:

A. The relationships between division and multiplication.

B. The relationships between division and subtraction.

7. Ability to compose and decompose numbers and to use the properties of operations to solve fraction division problems:

A. Commutative law. 


\section{B. Distributive law.}

8. Ability to use a variety of computational approaches for fraction division and to provide a conceptually sound explanation for why they work:

A. Invert-and-multiply algorithm.

B. Decimal division algorithm.

C. "Maintain the value of a quotient" rule.

D. Common denominator algorithm. (Alenazi, 2014)

This framework of fraction division operation sense was used as the basis for developing a new instrument to measure pre-service teachers' fraction division operation sense. One suggested instrument by the literature (Nuhfer \& Knipp, 2003; Wirth \& Perkins, 2005) was a knowledge survey. A knowledge survey is an instrument that consists of learning objectives, which are presented as a large collection of questions organized based on Bloom's Taxonomy levels (knowledge, comprehension, application, analysis, synthesis, and evaluation). Students do not actually answer these questions. Rather, they read the questions, determine what they know and can do, and accordingly predict (using a rating scale) their confidence levels in competently answering each question if they were to appear on an actual test. Clauss and Geedey (2010) argued that knowledge surveys are a useful tool that can be used to assess, monitor, and thus help enhance student learning. Pre-course knowledge surveys can provide information regarding student learning needs while the post-course ones can provide insight into student learning gains. Knowledge surveys can be also used throughout a course to monitor student learning.

\subsection{Instrument Development}

A panel of experts participated throughout the development process of a Fraction Division Operation Sense Knowledge Survey (FDOSKS) by providing opinions, comments, and suggestions in order to ensure a high level of internal content validity. The development process involved two phases. The first phase included item creation and instrument validation. Initially, the fraction division operation sense framework was transformed into fraction division problems. That is, candidate problems for each of the fraction division operation sense framework's eight dimensions were identified from the literature review, quizzes, exams, and other sources. Next, the identified problems were classified in accordance with the 6 Bloom's Taxonomy levels. As a result, a knowledge survey with high volume problems that cover the entire framework of fraction division operation sense was created. Due to such high volume of questions, only 12 problems (i.e., two items per Bloom level) were sampled from the original knowledge survey to create a representative FDOSKS (Fig.1).

The 12-item FDOSKS included at least one problem from each dimension of the fraction division operation sense framework. Since the fraction division operation sense framework dimensions are intertwined, one fraction division problem can measure mainly one dimension and partially another dimension. For example, the problem "create a story problem for $5 / 8 \div 3$ " measures one's ability to use a real-world situation for fraction division (i.e., dimension 3). It also measures this person's understanding of fraction division interpretations (i.e., dimension 1). Thus, the entity of this knowledge survey is treated as a measurement for one general construct, i.e., fraction division operation sense.

A panel of pre-service teachers participated in assessing the FDOSKS's readability, clarity of language, and usability. The pre-service teachers were met individually for an hour. They were asked to predict their performance on the survey problems and then solve the problems as well. At the end of the meeting, they provided comments and suggestions. Their feedback was considered to improve the instrument and make it ready for application.

In spite of the knowledge surveys' benefits, the extent to which pre-service teachers might be accurate in predicting their actual performance was of concern. Thus, I used the FDOSKS after the first phase to investigate pre-service teachers' accuracy of predicting their actual fraction division performance. To do so, 13 pre-service teachers at a Midwestern University in the USA individually predicted, without any written calculations, the score they would get on each fraction division problem. They used a scale ranging from 0 to $3(0=I$ cannot begin to answer this problem; $1=I$ can partially answer this problem; $2=I$ can answer most of the problem; and $3=$ I can answer the entire problem with full confidence).

After predicting scores for the entire 12-problem set, the pre-service teachers solved these problems. Prediction scores and actual scores were compared using two different approaches to determine the prediction accuracy. Interviews were conducted to determine factors affected prediction accuracy. The 
results were promising and indicated that these pre-service teachers displayed adequate accuracy in predicting their own performance of fraction division (Alenazi, 2014).

During the second phase, the FDOSKS was administered to different participants in order to evaluate its reliability. The participants only predicted the score they would get on each fraction division problem and results were used to compute Cronbach's alpha and Pearson's correlation coefficient. Thus, the main aim of this present study is to report on the reliability analyses of the FDOSKS.

\begin{tabular}{|c|c|c|c|c|c|}
\hline Bloom Level & $\begin{array}{l}\text { Fraction Division Questions } \\
\end{array}$ & \multicolumn{4}{|c|}{ Scale } \\
\hline Knowledge & $\begin{array}{l}\text { 1. Write a definition for the term fraction. } \\
\text { 2. Write a definition for the term division. }\end{array}$ & $\begin{array}{l}0 \\
0\end{array}$ & $\begin{array}{l}1 \\
1\end{array}$ & $\begin{array}{l}2 \\
2\end{array}$ & $\begin{array}{l}3 \\
3\end{array}$ \\
\hline Comprehension & $\begin{array}{l}\text { 3. You are making up word problems for your students. } \\
\text { Which of the following word problem(s) can be used to } \\
\text { represent } 3 \div 1 / 4 \text { ? (Circle all that apply.) } \\
\text { A. } 3 \text { cups of orange juice fill up exactly } 1 / 4 \text { of a } \\
\text { container. How many cups will fill the whole } \\
\text { container? } \\
\text { B. } 3 \text { friends each have } 1 / 4 \text { of a cookie. How many } \\
\text { cookies would they have if they put them all } \\
\text { together? } \\
\text { C. In a survey, } 3 \text { students said they prefer pizza. } \\
\text { These three students represent } 1 / 4 \text { of the number } \\
\text { of students who prefer a hamburger. How many } \\
\text { prefer the hamburger? } \\
\text { D. How many lengths of } 1 / 4 \text { yard can be cut from } 3 \\
\text { yards of cloth? } \\
\text { 4. Explain in your own words how to find the length of a } \\
\text { rectangle with an area of } 23 / 5 \text { square meters and a width } \\
\text { of } 2 / 3 \text { meters. } \\
2 / 3 m, 23 / 5 m^{2}\end{array}$ & 0 & 1 & 2 & 3 \\
\hline Application & $\begin{array}{l}\text { 5. Solve the problem } 13 / 4 \div 1 / 4 \text { using the distributive law. } \\
6 \text {. Solve the problem } 4 / 5 \div 1 / 4 \text { using decimals. }\end{array}$ & $\begin{array}{l}0 \\
0\end{array}$ & $\begin{array}{l}1 \\
1\end{array}$ & $\begin{array}{l}2 \\
2\end{array}$ & $\begin{array}{l}3 \\
3\end{array}$ \\
\hline Analysis & $\begin{array}{l}\text { 7. One of Mr. Smith's students created an incorrect real- } \\
\text { world problem to represent } 5 \div 1 / 2 \text { as follows: } \\
\text { Sara has } 5 \text { pizzas and she wants to give half of them to her } \\
\text { friend. How much pizza will her friend get? } \\
\text { Examine the student's misconception. } \\
8 \text {. One of Mr. Smith's students solved the problem } \\
3 / 4 \div 1 / 4 \text { by dividing the numerators and denominators: } \\
\frac{31}{44} \text {. He got } 3 \text {, which is the correct answer. } \\
\text { Explain if his method is always correct. }\end{array}$ & 0 & 1 & 2 & 3 \\
\hline Synthesis & $\begin{array}{l}\text { 9. Create a story problem for } 5 / 8 \div 3 \text {. } \\
\text { 10. Create a story problem for } 3 / 4 \div 1 / 3 \text {. }\end{array}$ & $\begin{array}{l}0 \\
0\end{array}$ & $\begin{array}{l}1 \\
1\end{array}$ & $\begin{array}{l}2 \\
2\end{array}$ & $\begin{array}{l}3 \\
3\end{array}$ \\
\hline Evaluation & $\begin{array}{l}\text { Discuss the validity of following statements: } \\
\text { 11. The answer does not always get smaller when I divide. } \\
\text { 12. Dividing by a number is always equivalent to multiplying } \\
\text { by its reciprocal. }\end{array}$ & $\begin{array}{l}0 \\
0\end{array}$ & $\begin{array}{l}1 \\
1\end{array}$ & $\begin{array}{l}2 \\
2\end{array}$ & $\begin{array}{l}3 \\
3\end{array}$ \\
\hline
\end{tabular}

Figure.1 Fraction Division Operation Sense Knowledge Survey (FDOSKS)

$(0=I$ cannot begin to answer this problem; $1=I$ can partially answer this problem; $2=I$ can answer most of the problem; and $3=$ I can answer the entire problem with full confidence).

\section{METHODOLOGY}

\subsection{Sample}

A sample of 113 male pre-service teachers aged 20-23 was randomly recruited form 3 different schools of education (northern, central, and southern) in Saudi Arabia to participate in this present study. The participants needed to successfully complete a four-year program in order to graduate and become certified 
elementary school teachers majoring in special education. They were required to study two mathematics courses: Math1 and Math2. These courses focus on elementary school mathematics, including the topic of fraction division, to prepare teachers to teach mathematics. Only those who attended and successfully completed the mathematics courses filled out this study's survey.

\subsection{Measure}

The FDOSKS was administered to participants. Internal content validity of the FDOSKS was established following an extensive item creation, instrument validation, and pilot testing by the researcher and an expert advisory committee of four members. For the purpose of this study, the researcher (mathematical education major) and two other English major faculty members whose first language is Arabic translated the FDOSKS from its original English version into Arabic. The translation was done individually and then discussed in a meeting until consensus was reached. After translation, two mathematics education major faculty members reviewed the instrument to ensure the appropriateness of the mathematics education terminology.

\subsection{Procedures}

One hundred and thirteen pre-service teachers completed a printed version of the FDOSKS, which took approximately 15 minutes or less. The survey was administered and collected by a faculty member in each school and delivered to the researcher later. The data collected from the survey was used to compute internal consistency (Cronbach's alpha). Cronbach's alpha was computed for the entire scale and for each level of Bloom Taxonomy. Internal consistency is a measure of the interrelationship of the instrument items and their ability measure the same general construct.

Of the 113 pre-serve teachers, 59 (52\%) completed the survey on two different occasions 14 days apart. The results from the two occasions were used to compute test-retest reliability (Pearson's correlation coefficient). Pearson's correlation coefficient was computed for the entire scale and for each level of Bloom Taxonomy. Test-retest reliability is a measure of the degree to which the instrument produces consistent results over time when applied by the same group of individuals. SPSS 22.0 Software was used to compute both internal consistency and test-retest.

\section{RESULTS}

\subsection{Test-retest Reliability}

Table 1 presents the results for test-retest reliability. Test-retest reliability (Pearson's correlation) was computed for the entire scale and for each level of Bloom Taxonomy.

Table 1. FDOSKS Knowledge Survey Test-retest Reliability

\begin{tabular}{|c|c|c|}
\hline Scale & Number of Items & Pearson's Correlation \\
\hline Total FDOSKS & 12 & $.929^{\star *}$ \\
\hline KN level & 2 & $.854^{\star *}$ \\
\hline CO level & 2 & $.703^{\star *}$ \\
\hline AP level & 2 & $.715^{\star \star}$ \\
\hline AN level & 2 & $.788^{\star \star}$ \\
\hline SY level & 2 & $.628^{\star *}$ \\
\hline EV level & 2 & $.715^{\star *}$ \\
\hline
\end{tabular}

$\mathrm{KN}$ : knowledge, CO: comprehension, AP: Application, AN: Analysis,

SY: Synthesis, EV: Evaluation.

\subsection{Internal Consistency}

Internal consistency (Cronbach's alpha) was computed for the entire scale and for each level of Bloom Taxonomy. The Cronbach's alpha for the total FDOSKS is .888. Table 2 presents the results for each level of Bloom Taxonomy. Table 3 presents certain item statistics that include the "corrected item- total correlation" and "Cronbach's alpha if item deleted" for each item of the scale. 
Table 2. Internal Consistency Reliability for each Bloom's Level

\begin{tabular}{c|c|c}
\hline & Number of items & Cronbach's alpha \\
\hline KN level & 2 & .762 \\
\hline CO level & 2 & .778 \\
\hline AP level & 2 & .883 \\
\hline AN level & 2 & .837 \\
\hline SY level & 2 & .970 \\
\hline EV level & 2 & .763 \\
\hline
\end{tabular}

Table 3. Item Statistics

\begin{tabular}{c|c|c}
\hline Item & $\begin{array}{c}\text { Corrected Item- } \\
\text { Total Correlation }\end{array}$ & $\begin{array}{c}\text { Cronbach's Alpha if } \\
\text { Item Deleted }\end{array}$ \\
\hline 1 & .491 & .884 \\
\hline 2 & .590 & .879 \\
\hline 3 & .530 & .882 \\
\hline 4 & .619 & .877 \\
\hline 5 & .639 & .876 \\
\hline 6 & .458 & .886 \\
\hline 7 & .532 & .882 \\
\hline 8 & .457 & .887 \\
\hline 9 & .722 & .871 \\
\hline 10 & .715 & .871 \\
\hline 11 & .631 & .877 \\
\hline 12 & .724 & .871 \\
\hline
\end{tabular}

\section{DISCUSSION AND CONCLUSION}

The main aim of the present study was to evaluate the reliability of the FDOSKS. The results are promising and are discussed in details according to the reliability type.

\subsection{Test-Retest Reliability}

Hnikle, Wiersma, and Jurs (2003) proposed cut-off values for interpreting the size of a correlation coefficient. They considered values between 1 and .9 as indicators of very high correlations while the values between .9 and .7, .7 and .5, and .5 and .3 indicate high, moderate, and low correlation, respectively. Values lower than 0.3 exhibit little correlation, if any.

The results of the present study show that the test-retest reliability value for the total FDOSKS is .929. The values for Bloom's levels 1 through 6 were $.854, .703, .715, .788, .628$, and .715 , respectively. The moderate value of .628 and a moderately high value, such as .703 , may have been due to the low number of items per Bloom level (i.e., 2 items) or a limited rating scale range (i.e., 0 to 3). With a correlation value of .929 for the total score of the scale and .628 as the lowest correlation value for a Bloom level, the FDOSKS is considered stable over time.

\subsection{Internal Consistency}


Cronbach's alpha reliability coefficient values ranged from 0 to 1 , with values closer to 1.0 indicating greater internal consistency of the items in the scale. Many studies consider a reliability score of .7 as the lowest acceptable value for an instrument to be reliable. Values greater than 9 are considered too high; thus, may indicate a high level of item redundancy, suggesting that a number of items are testing the same thing but in different ways (Tavakol \& Dennick, 2011). In the present study, Cronbach's alpha value for the total score of the scale was .888. For Bloom's levels 1 through 6 , the values were .762, .778, .883, .837, .97, and .763, respectively. With the lowest value being .762, the FDOSKS is considered to have adequate internal consistency, although the Cronbach's alpha for fifth Bloom's level (i.e. the synthesis level) was too high (.97).

The elevated value of the synthesis level (.97) may suggest that item 9 and item 10 are measuring the same thing. The two items, "create a story problem for $5 / 8 \div 3$ " and "create a story problem for $3 / 4 \div 1 / 3$," may appear to measure the same thing; however, they are not. The two problems have different structure where $5 / 8 \div 3$ has a quotient of less than one and $3 / 4 \div 1 / 3$ has a quotient greater than one. According to $\mathrm{Li}$ and Smith (2007), $3 / 4 \div 1 / 3$ is deemed easier to solve. It is easier to determine how many $1 / 3$ s are in $3 / 4$ (i.e., $3 / 4$ $\div 1 / 3$ ) than to find how many 3 s are in $5 / 8$ (i.e. $5 / 8 \div 3$ ). Thus, a high achieving participant who is able to solve $5 / 8 \div 3$ is more likely to solve $3 / 4 \div 1 / 4$. Conversely, a low achieving participant who is unable to solve $3 / 4 \div 1 / 3$ is expected to struggle with $5 / 8 \div 3$. This may suggest that most participants could be, at least when considering these two problems, high achieving, low achieving participants, or a mixture of both. Deleting one of these items would not have any positive effect on reliability. This statement is discussed in details in the discussion of alpha if an item was deleted below.

In Table 3, the "corrected item-total correlation" shows the correlation between one item and the sum score of the rest of items. A value less than .3 would indicate that the item is not measuring what it was designed to measure, and this may suggest the item to be revised or removed. The correlations for this study's items ranged from .457 for item 8 to and .724 for item 12. Such range indicates that higher score on each item is associated with higher scores on the scale. Accordingly, this range is encouraging and denotes that each item is a good indicator of the construct.

The "alpha if item deleted" column estimates the Cronbach's alpha coefficient if a certain item was eliminated from the scale. Meyers, Gamst, and Guarino (2013) explained that, "with good quality items in a short scale...the alpha coefficient does not change dramatically, although it tends to get slightly lowered for most of the items (p. 25)". As shown in Table 3, the alpha coefficient value ranges from .871(the lowest value) for items 9,10 , and 12 to .887 (the highest value) for item 8 . The highest value (.887) is less than the Cronbach's alpha of scale total score (.888), which eliminates the need to delete any item to enhance reliability. The lowest value (.871) also indicates that deleting any of the items with the lowest value would not significantly decrease the Cronbach's alpha for the whole scale. These Cronbach's alpha values confirm that the scale has adequate internal consistency.

In conclusion, the FDOSKS in this study showed adequate internal consistency and test-retest reliability. The results indicated that the FDOSKS is a promising instrument for measuring pre-service teachers' fraction division operation sense. The FDOSKS could be used to diagnose pre-service teachers' fraction division operation sense pre-course or post-course. This diagnosis would provide instructors with useful information to enhance pre-service teachers' fraction division operation sense. It could also be used as a selfassessment tool that would allow pre-service teachers to monitor their learning of fraction division over time as well as direct and enhance their own learning. The limitation of the present study is its generalizability. The results of the study were based on a small sample of male participants, which limits the study's generalizability to other populations. The study may have yielded different results if the sample was larger and included females.

\section{REFERENCE LIST}

Alenazi, A. (2014). Understanding Pre-service Teachers' Self-assessment: The Case of Fraction Division. Available from ProQuest Dissertations and Theses database. (Document ID 1564773522).

Ball, D. L. (1990). The mathematical understandings that prospective teachers bring to teacher education. The Elementary School Journal. 90(4): 449-466. Beckmann, S. (2010).

Mathematics for Elementary Teachers ( $\left.3^{\text {rd }} \mathrm{ed}\right)$, Boston, MA: Addison-Wesley.

Clauss, J., \& Geedey, K. (2010). Knowledge Surveys: Students Ability to Self-Assess. Journal of the

Scholarship of Teaching and Learning, 10 (2), 14-24.

Hinkle, D. E., Wiersma, W., \& Jurs, S. G. (2003). Applied statistics for the behavioral sciences. Boston, 
Mass: Houghton Mifflin.

Huinker D. (2002). Examining dimensions of fraction operation sense. In B. Litwiller (Ed.) Making sense of fractions, ratios, and proportions Reston, VA: National Council of Teachers

of Mathematics. 72-78.

Li Y, Smith D. (2007). Prospective middle school teachers' knowledge in mathematics and pedagogy for teaching - The case of fraction division. In J. H. Woo, H. C. Lew, K. S. Park, \& D. Y. Seo (Eds.),

Proceedings of the 31st conference of the international group for the Psychology of Mathematics Education, Vol. 3, pp. 185-192. Seoul, The Republic of Korea: PME.

Lubinski C, Fox T, Thomason R. (1998). Learning to make sense of division of fractions: One K-8 preservice teacher's perspective. School Science and Mathematics. 98:247-259.

Ma L. (1999). Knowing and teaching elementary mathematics: Teachers' understanding of fundamental mathematics in China and the United States. Mahwah, NJ: Lawrence Erlbaum Associates.

Meyers, L.S., Gamst, G., \& Guarino, A.J. (2013a). Performing data analysis using IBM SPSS. Hoboken, NJ: Wiley.

Nillas, L. (2003). Division of fractions: Preservice teachers' understanding and use of problem solving strategies. The Mathematics Educator,7(2), 96 - 113.

Nuhfer, E., \& Knipp, D. (2003). The knowledge survey: A tool for all reasons. To Improve the Academy, 21, 59.

Orrill, C., Araujo, Z., \& Jacobson, D. (2010). Teachers' emerging understanding of fractions division as proportional reasoning in professional development. Paper presented at the 2010 Annual Meeting of the American Educational Research Association, San Diego.

Petit, M., Laird, R., \& Marsden, E. (2010). A focus on fractions. New York, NY: Routledge.

Simon, M. (1993). Prospective elementary teachers' knowledge of division. Journal for Research in Mathematics Education, 24, 233-254.

Tavakol, M. \& Dennick, R. (2011). Making sense of Cronbach's alpha," International Journal of Medical Education, vol. 2, pp. 53-55.

Tirosh D. (2000). Enhancing prospective teachers' knowledge of children's misconceptions: The case of division of fractions. Journal for Research in Mathematics Education. 31(1), 5-25.

Wirth, K. R., \& Perkins, D. (2005). Knowledge surveys: An indispensable course design and assessment tool. Innovations in the Scholarship of Teaching and Learning. Retrieved January 13, 2011: http://www.macalester.edu/geology/wirth/WirthPerkinsKS.pdf 